\title{
Immunoinflammatory, Thrombohaemostatic, and Cardiovascular Mechanisms in COVID-19
}

\author{
Selin Gencer ${ }^{1, *}$ Michael Lacy ${ }^{1,2, *}$ Dorothee Atzler ${ }^{1,2,3} \quad$ Emiel P. C. van der Vorst ${ }^{1,2,4,5}$ \\ Yvonne Döring ${ }^{1,2,6}$ Christian Weber ${ }^{1,2,7,8, * *}$
}

${ }^{1}$ Institute for Cardiovascular Prevention, Ludwig-MaximiliansUniversität, Munich, Germany

${ }^{2}$ DZHK (German Center for Cardiovascular Research), Partner Site Munich Heart Alliance, Munich, Germany

${ }^{3}$ Walther Straub Institute for Pharmacology and Toxicology, LudwigMaximilians-Universität, Munich, Germany

${ }^{4}$ Interdisciplinary Center for Clinical Research (IZKF), Institute for Molecular Cardiovascular Research (IMCAR), RWTH Aachen University, Aachen, Germany

${ }^{5}$ Department of Pathology, Cardiovascular Research Institute Maastricht (CARIM), Maastricht University, Maastricht, The Netherlands

6 Divison of Angiology, Swiss Cardiovascular Center, Inselspital, Bern University Hospital, University of Bern, Switzerland

${ }^{7}$ Department of Biochemistry, Cardiovascular Research Institute Maastricht (CARIM), Maastricht University Medical Centre, Maastricht, The Netherlands

8 Munich Cluster for Systems Neurology (SyNergy), Munich, Germany

\author{
Address for correspondence Michael Lacy, MSc, Institute for \\ Cardiovascular Prevention, Ludwig-Maximilians University Munich, \\ Pettenkoferstr. 9, D-80336, Munich, Germany \\ (e-mail: Michael.Lacy@med.uni-muenchen.de; \\ chweber@med.Imu.de).
}

Thromb Haemost 2020;120:1629-1641.
Abstract
Keywords
- COVID-19
- SARS-CoV-2
- cardiovascular disease
- inflammation
- thrombosis
- RAAS
- ACE2

The global coronavirus disease 2019 (COVID-19) pandemic has deranged the recent history of humankind, afflicting more than 27 million individuals to date. While the majority of COVID-19 patients recuperate, a considerable number of patients develop severe complications. Bilateral pneumonia constitutes the hallmark of severe COVID-19 disease but an involvement of other organ systems, namely the cardiovascular system, kidneys, liver, and central nervous system, occurs in at least half of the fatal COVID-19 cases. Besides respiratory failure requiring ventilation, patients with severe COVID-19 often display manifestations of systemic inflammation and thrombosis as well as diffuse microvascular injury observed postmortem. In this review, we survey the mechanisms that may explain how viral entry and activation of endothelial cells by severe acute respiratory syndrome coronavirus 2 can give rise to a series of events including systemic inflammation, thrombosis, and microvascular dysfunction. This pathophysiological scenario may be particularly harmful in patients with overt cardiovascular disease and may drive the fatal aspects of COVID-19. We further shed light on the role of the renin-angiotensin aldosterone system and its inhibitors in the context of COVID-19 and discuss the potential impact of antiviral and anti-inflammatory treatment options. Acknowledging the comorbidities and potential organ injuries throughout the course of severe COVID-19 is crucial in the clinical management of patients affecting treatment approaches and recovery rate.

\footnotetext{
* These authors contributed equally to this manuscript and share first authorship.

** The review process for this paper was fully handled by Gregory Y. H. Lip, Editor-in-Chief.
}

received July 3, 2020 accepted after revision September 14, 2020 (c) 2020. Thieme. All rights reserved. Georg Thieme Verlag KG,

Rüdigerstraße 14,

70469 Stuttgart, Germany
DOI https://doi.org/ 10.1055/s-0040-1718735. ISSN 0340-6245. 


\section{Introduction}

The novel coronavirus disease 2019 (COVID-19) has rapidly progressed to a global pandemic infecting over 23 million people in 188 countries by the middle of August $2020 .^{1}$ The basis underlying COVID-19 is infection with severe acute respiratory syndrome coronavirus 2 (SARS-CoV-2), which originates from the Coronaviridae family of viruses that are usually associated with respiratory infections. ${ }^{2,3}$ Although the respiratory manifestations of COVID-19 are well documented, ${ }^{4,5}$ recent studies have also observed cardiovascular complications in patients. ${ }^{6,7}$ Viral infection is associated with increased inflammatory biomarkers including interleukin-6 (IL-6) and D-dimer, ${ }^{8}$ which may influence severe cardiovascular clinical features such as thrombosis and cardiac injury as observed in limited cohorts of COVID-19 patients. ${ }^{9-11}$

It is well established that outbreaks of acute respiratory infections such as influenza may trigger an increase in coronary deaths due to myocardial infarction or stroke. ${ }^{12,13}$ Previously, similar viral epidemics including severe acute respiratory syndrome (SARS) reported common cardiovascular complications such as acute myocardial infarction and increased susceptibility to thrombosis. ${ }^{14,15}$ In the case of SARS-CoV-2, however, the risk of ischemic stroke was 7.5fold higher than that of influenza patients. ${ }^{16}$ Furthermore, emerging evidence from the current COVID-19 pandemic suggests that individuals with preexisting cardiovascular risk factors including heart failure, hypertension, and diabetes may be more susceptible to severe infection.,17-19

Although the interactions between COVID-19 and cardiovascular inflammation require further investigation, this review will focus on the potential mechanisms by which SARS-CoV-2 infects its host with a particular focus on vascular endothelial cell dysfunction. Specifically, we seek to describe the immunoinflammatory mechanisms that may disproportionately affect COVID-19 patients with underlying cardiovascular pathologies leading to their hypercoagulable states and cardiac injury. Finally, we discuss promising therapeutic options targeting the hyperinflammation associated with severe SARS-CoV-2 infection.

\section{Mechanisms of Cellular Entry and Infection}

Viruses cause infections in hosts by entering the cells to exploit the cellular machinery of the host to further replicate and spread from cell to cell. It has been established that the SARSCoV-2 uses the protein angiotensin-converting enzyme-2 (ACE2) efficiently, even more so than the original SARS-CoV, to invade the host cells. ${ }^{20-22}$ ACE2 is an extensively present cell surface enzyme. Li and colleagues recently analyzed the expression of ACE2 across 31 human tissues using datasets provided from Genotype-Tissue Expression (GTEx) and The Cancer Genome Atlas (TCGA). They found the highest expression of the receptor in the small intestines, testes, kidneys, heart, thyroid, and adipose tissue, whereas the lowest expression was observed in the blood, spleen, bone marrow, blood vessels, and muscle. ${ }^{23}$ Moderate expression levels were reported in the lungs, colon, liver, bladder, and adrenal gland. Nevertheless, these findings do not specify cell-specific expression of the receptor and remain to be further validated in protein levels. A study by Chen et al examined the cellular expression of ACE2 in the human heart via single nuclear transcriptome analysis and found that ACE2 expression was low in cardiomyocytes, whereas it was high and specific to pericytes. ${ }^{24}$ Moreover, another study by Nicin and colleagues using single nuclei RNA sequencing likewise reported ACE2 expression particularly in pericytes. ${ }^{25}$ They also reported the expression of the receptor in cardiomyocytes as well as mural cells and lower levels of expression were also observed in fibroblasts, endothelial cells, and leukocytes. Furthermore, cardiomyocyte expression of ACE2 was found to be significantly increased in patients with heart disease. The extensive presence of this receptor may be an explanation to the wide spectrum of symptoms and complications of COVID-19, such as respiratory and gastrointestinal distress, loss of taste and smell, and multiorgan dysfunction including cardiac and liver injury as well as renal failure. ACE2 is a central regulator in the renin-angiotensin aldosterone system (RAAS), a hormone system crucial for the maintenance of blood pressure as well as the fluid and electrolyte homeostasis in the body ( Table 1). ${ }^{26}$ Imbalances in RAAS can lead to hypertension, and the components of this system are known to further augment cardiovascular risk factors such as inflammation, thrombosis, insulin resistance, and obesity ( - Table 1). ${ }^{27}$ Therefore, the doorway receptor of SARS-CoV-2, ACE2, plays a pivotal role in cardiovascular health and disease among other factors.

RAAS is activated in response to renin released by kidneys in the events of low blood supply and low sodium load. Circulating renin then cleaves its substrate angiotensinogen produced by the liver, which produces the peptide hormone angiotensin I. Predominantly occurring in the lungs, angiotensin I is further cleaved by ACE to produce angiotensin II (-Table 1). ${ }^{28}$ Angiotensin II constricts blood vessels and increases blood pressure to replenish the blood supply to the kidneys in addition to stimulating aldosterone synthesis in the adrenal cortex for renal sodium reabsorption. ${ }^{29}$ Consequently, RAAS activation leads to increased blood pressure and pharmacological blockade of the RAAS via ACE inhibitors (ACEis) and angiotensin II receptor blockers (ARBs) are used widely to treat hypertension in patients suffering from cardiovascular disease (CVD). ${ }^{27}$

While the RAAS is fulfilling its aim in assisting the kidneys via the effects of angiotensin II, its impact on the vasculature can introduce adverse cardiac outcomes such as left ventricular hypertrophy due to hypertension. ${ }^{30}$ This impact may be further detrimental especially in the case of present underlying risks for CVDs including atherosclerosis. Angiotensin II and its receptor angiotensin II receptor type $\mathrm{I}\left(\mathrm{AT}_{1}\right)$ promote inflammation at the vascular wall by several mechanisms including increased oxidative stress via reactive oxygen species, NF-kB-mediated adhesion molecule expression, and cytokine and chemokine release (-Table 1). ${ }^{31}$ These events vastly contribute to endothelial dysfunction and arterial leukocyte recruitment, which are major drivers of atherosclerotic plaque development. ${ }^{28}$ Moreover, RAAS has been shown to enhance insulin resistance. In the clinic, it could be demonstrated that type II diabetes in humans may be dependent on actions of angiotensin II as 
Table 1 The role of RAAS in cardiovascular comorbidities associated with severe COVID-19 infection

\begin{tabular}{|c|c|c|}
\hline Pathology & Relevant role of RAAS & References \\
\hline \multirow[t]{3}{*}{ Hypertension } & $\begin{array}{l}\text { - RAAS is activated in response to renin released by kidneys with low blood supply and it increases blood } \\
\text { pressure via its vasoconstrictive hormone angiotensin II }\end{array}$ & $26-28$ \\
\hline & $\begin{array}{l}\text { - Zhong et al showed that angiotensin II infusion in ACE2-deficient mice leads to hypertension as well as } \\
\text { diastolic dysfunction }\end{array}$ & 55 \\
\hline & $\begin{array}{l}\text { - In contrast to angiotensin II produced by ACE, angiotensin (1-7) produced by ACE2 acts as a } \\
\text { vasodilator and reduces blood pressure }\end{array}$ & $26-28$ \\
\hline \multirow{3}{*}{$\begin{array}{l}\text { Insulin } \\
\text { resistance }\end{array}$} & - RAAS is shown to enhance insulin resistance and thus type II diabetes in humans via angiotensin II & 32,33 \\
\hline & $\begin{array}{l}\text { - RAAS inhibition by losartan, an angiotensin receptor blocker, in patients showed improved insulin } \\
\text { resistance as well as glucose homeostasis }\end{array}$ & 148 \\
\hline & $\begin{array}{l}\text { - Angiotensin (1-7)/MasR axis is shown to promote glucose uptake by rat skeletal muscle in vivo and } \\
\text { thereby improves insulin sensitivity }\end{array}$ & 43 \\
\hline \multirow[t]{2}{*}{ Obesity } & - RAAS is activated in adipose tissue during obesity and promotes adipocyte growth and inflammation & 36,39 \\
\hline & - Components of the RAAS were shown to be increased in obese patients & $34,35,38$ \\
\hline \multirow[t]{2}{*}{$\begin{array}{l}\text { Endothelial } \\
\text { dysfunction }\end{array}$} & $\begin{array}{l}\text { - } \mathrm{AT}_{1} \text { receptor in activated RAAS drives endothelial oxidative stress and adhesion molecule expression } \\
\text { via the NF-kB pathway, thus impairs endothelial function }\end{array}$ & 28,31 \\
\hline & - Angiotensin (1-7)/MasR axis promotes nitric oxide release & 44 \\
\hline \multirow[t]{3}{*}{ Inflammation } & $\begin{array}{l}\text { - Angiotensin II-AT } 1 \text { axis promotes inflammation at the vascular wall via increased oxidative stress and } \\
\text { NF-kB-mediated adhesion molecule expression along with cytokine and chemokine release }\end{array}$ & 31,149 \\
\hline & $\begin{array}{l}\text { - Angiotensin II supports endothelium-immune cell adhesion by stimulating endothelial vascular cell } \\
\text { adhesion molecule-2 via NF-kB }\end{array}$ & 149 \\
\hline & $\begin{array}{l}\text { - ACE2/angiotensin (1-7) axis exerts anti-inflammatory and antifibrotic effects by inhibiting the } \\
\text { MAPK/NF-kB pathway }\end{array}$ & 45,46 \\
\hline
\end{tabular}

Abbreviations: $\mathrm{ACE} 2$, angiotensin-converting enzyme-2; $\mathrm{AT}_{1}$, angiotensin II receptor type I; RAAS, renin-angiotensin aldosterone system.

several studies have shown improved insulin resistance in patients treated with ACEis as well as ARBs (- Table 1). ${ }^{32,33}$

Furthermore, additional components of RAAS, such as aldosterone, renin, and angiotensinogen, were shown to be elevated in the circulation of obese patients revealing a significant link between RAAS and obesity (- Table 1). ${ }^{34-38}$ RAAS is also upregulated locally in adipose tissue during obesity, which links angiotensin II to increased adipocyte growth and inflammation within the tissue. ${ }^{39,40}$ In conclusion, activation of RAAS and thus its predominant effector hormone, angiotensin II, introduces several deleterious consequences which are critical mechanisms driving the pathophysiology of CVDs and its comorbidities. ${ }^{41}$ The key switch antagonizing angiotensin II-driven effects of RAAS is the action of ACE2. Although structurally homologous to ACE, the physiological function of ACE2 is actually to counterbalance the functions of $A C E$ and to establish a vital equilibrium in RAAS. ${ }^{42}$ By hydrolyzing angiotensin II, ACE2 produces angiotensin (1-7) and ultimately diminishes angiotensin II levels and function. Moreover, angiotensin (1-7) reduces blood pressure by acting as a vasodilator in contrast to angiotensin II. Angiotensin (1-7) and its receptor MAS1 oncogene (Mas) offer further cardioprotective effects such as reduced insulin resistance, antithrombotic effects through nitric oxide release, and decreased inflammation by NF-kB pathway blockade (- Table 1). ${ }^{43-46}$ Therefore, ACE2 is a crucial regulator of RAAS, overcoming its hostile side effects and thereby supporting cardiac health. ${ }^{47}$

In spite of its extensively protective roles as mentioned above, ACE2 provides an invasion pathway to SARS-CoV-2 via its extracellular domain that is recognized and targeted by the virus to gain intracellular access. ${ }^{48}$ The virus expresses a class I fusion protein, known as the Spike (S) protein, on its envelope establishing its characteristic "crown-like" exterior hence its name "corona." 49 The S protein facilitates the engagement of the virus to the host cell via its subunit $\mathrm{S}$, which possesses the binding region to the extracellular domain of ACE2. ${ }^{50}$ Viral attachment is followed by fusion and internalization of the virus into the target cell via the $\mathrm{S}$ protein subunit $\mathrm{S2} .{ }^{51}$ A crucial event enabling the $\mathrm{S} 2$ subunit-driven fusion is the priming of the $\mathrm{S}$ protein, which is executed by the host transmembrane protease serine 2 (TMPRSS2). Notably, TMPRSS2 is expressed in endothelial cells giving rise to their susceptibility as a target cell. Confirming its role in viral entry, an inhibitor of this serine protease involved in $S$ protein priming can block cellular SARSCoV-2 entry. ${ }^{20,52}$ Internalization of the virus entails endocytosis of the virus presumably along with its bound receptor ACE2. As a result, the virus entry eliminates ACE2 from the cell surface and subsequently attenuates the receptor activity and its protective roles through the angiotensin (1-7)-Mas pathway leading to unbalanced RAAS. ${ }^{47,53}$ This is supported by the findings that SARS-CoV-infected mice displayed reduced ACE2 levels in their lungs, which was likewise observed upon the recombinant SARS S protein treatment. ${ }^{54}$ Moreover, Zhong and colleagues showed that angiotensin II infusion in ACE2deficient mice led to hypertension, pathological hypertrophy, myocardial fibrosis, and diastolic dysfunction. However, this phenotype was alleviated in wild-type mice with recombinant human ACE2 (- Table 1). ${ }^{55}$ Therefore, in addition to the known pulmonary consequences of COVID-19-related inactivation of 
ACE2 receptors such as the acute respiratory distress syndrome (ARDS), ACE2 inactivation has great potential to also impair cardiovascular health in several ways. ${ }^{56,57}$ Low ACE2 expression, due to various reasons such as older age, diabetes, or hypertension, in patients may increase the severity of SARSCoV-2 infection. ${ }^{58}$ This notion is also in line with the epidemiological statistics revealing that significant numbers of patients facing serious and even fatal manifestations of the COVID-19 consist of elderly and CVD patients. ${ }^{59}$

\section{SARS-CoV-2 and Endothelial Dysfunction}

As mentioned previously, SARS-CoV-2 can promote endothelial dysfunction by shifting the balance in RAAS to the angiotensin II/AT 1 axis, which elevates oxidative stress and inflammation. Endothelial dysfunction is characterized by a decrease in nitric oxide levels as a consequence of impaired endothelial nitric oxide synthase function. Nitric oxide is a vasodilator and its deficiency leads to hypertension by constricting the blood vessels, and it can further elicit thrombosis and vascular inflammation. ${ }^{60-62}$ In addition to the RAAS-mediated effects, emerging evidence revealed that SARS-CoV-2 can also directly cause endothelial dysfunction by infecting endothelial cells. Varga and colleagues showed accumulation of viral bodies in endothelial cells of several organs, including the kidneys and small intestines, from COVID-19 patients, which was accompanied by increased endothelial cell inflammation and apoptosis. ${ }^{63}$ The authors also reported "lymphocytic endotheliitis in lung, heart, kidney, and liver." ${ }^{63}$ Moreover, SARS-CoV-2 induces systemic inflammation in the host leading to significantly increased levels of proinflammatory cytokines in the circulation, such as IL-6 and tumor necrosis factor- $\alpha$ (TNF- $\alpha) .{ }^{17}$ As the vascular endothelium forms a protective layer between the organs and the circulatory system, endothelial cells are constantly exposed to various circulating molecules. Therefore, in the event of SARS-CoV-2-induced cytokine release, endothelial cells are primarily influenced by the potent effects of these inflammatory cytokines. Increased adhesion molecule expression and chemoattractant release are critical processes mediated by activated endothelial cells in response to inflammatory stimuli. These events further augment inflammation of the vascular wall by promoting leukocyte recruitment. In conclusion, SARS-CoV-2 can impair endothelial function by several mechanisms including direct-viral-infection-induced endotheliitis and endothelial injury leading to shifts in the angiotensin $\mathrm{II} / \mathrm{AT}_{1}$ axis and host inflammatory response.

Furthermore, Chen et al point out that pericytes express high levels of ACE2, which was especially increased in patients with basic heart failure leading to their evaluation of pericytes as the "cardiac target cell of SARS-CoV-2."24 Additionally, the authors speculated that pericyte injury may lead to endothelial dysfunction at the capillary level and might compromise the microcirculation. Further complicating the issue, recent reports on detection of SARS-CoV2 in the central nervous system (CNS) of COVID-19 patients support the notion that severe illness may be due to CNS involvement and neurological manifestations. ${ }^{64}$ In the case of CNS involvement, it is clear that the blood-brain barrier and its endothelium represent a unique setting compared with other endothelial cells in the body due to its specific expression of enzymes and transport molecules. ${ }^{65}$ Evidence from earlier SARS and MERS outbreaks suggest that SARSCoV-2 likely invades the CNS through ACE2 as it does with other tissues; however, additional molecules including CD147 may also play a role in viral entry. ${ }^{66}$

Endothelial dysfunction is a common theme for numerous conditions known to be especially disadvantageous for COVID-19 patients including CVDs and their comorbidities. ${ }^{67}$ SARS-CoV-2-driven systemic endothelial cell injury raises the threat of multiple organ failure, and patients who are already suffering from impaired endothelial function due to underlying conditions, like CVDs, are at much higher risk for severe complications of COVID-19. Accordingly, treatment strategies aimed at restoring endothelial function in COVID19 patients, such as tackling nitric oxide deficiency, should be implemented strictly. For example, phosphodiesterase type 5 (PDE-5) inhibitors are used in the treatment of erectile dysfunction with the aim of restoring NO-mediated erectile smooth muscle relaxation, and the PDE-5 inhibitors, sildenafil and tadalafil, were shown to improve endothelial function by increasing flow-mediated vasodilation in patients with chronic heart failure and type 2 diabetes. ${ }^{68,69}$ In addition to its endothelial-protective effects, nitric oxide is proven to protect against the original SARS-CoV. Akerström et al showed that nitric oxide interferes with $S$ protein and ACE2-mediated viral fusion mechanism while also inhibiting viral replication in the early stages. ${ }^{70,71}$ Consumption of nitric oxide boosting foods, such as beetroot, may be beneficial to improve the endothelial function and to limit thrombus formation as well as viral infection. ${ }^{72}$ In addition, experimental modalities for directly and specifically protecting endothelial cells against damage-induced apoptosis, e.g., microRNA mimics, could be considered. ${ }^{73}$

\section{Inflammation}

While lung epithelial and vascular endothelial cell infection is the direct consequence of SARS-CoV-2, viral infection can also elicit severe systemic inflammation that may underlie the cardiovascular complications seen in COVID-19 patients. The severity of SARS-CoV-2 infection has been associated with immune cell dysregulation together with inflammatory cytokine storms (- Fig. 1). ${ }^{17,18}$

Pathological analysis of lungs from patients with COVID-19 compared with patients with influenza revealed similar total lymphocytic infiltration; however, CD4 + T cell subsets were increased in COVID-19 patients while CD8 $+\mathrm{T}$ cell subsets were decreased. ${ }^{74}$ More specifically, CD4+ T cells resembled proinflammatory CC-chemokine receptor $6($ CCR6 + ) T helper 17 (Th17) cells while CD8+ T cells harbored higher percentages of cytotoxic granules. ${ }^{75}$ A genome-wide association study from the Italian and Spanish epicenters observed an association between SARS-CoV-2 infection with polymorphisms at chromosome 3p21, which encodes a cluster genes for the ABO blood group as well as for chemokine receptors including chemokine receptor 9 (CCR9) and C-X-C motif receptor 6 (CXCR6). ${ }^{76}$ 


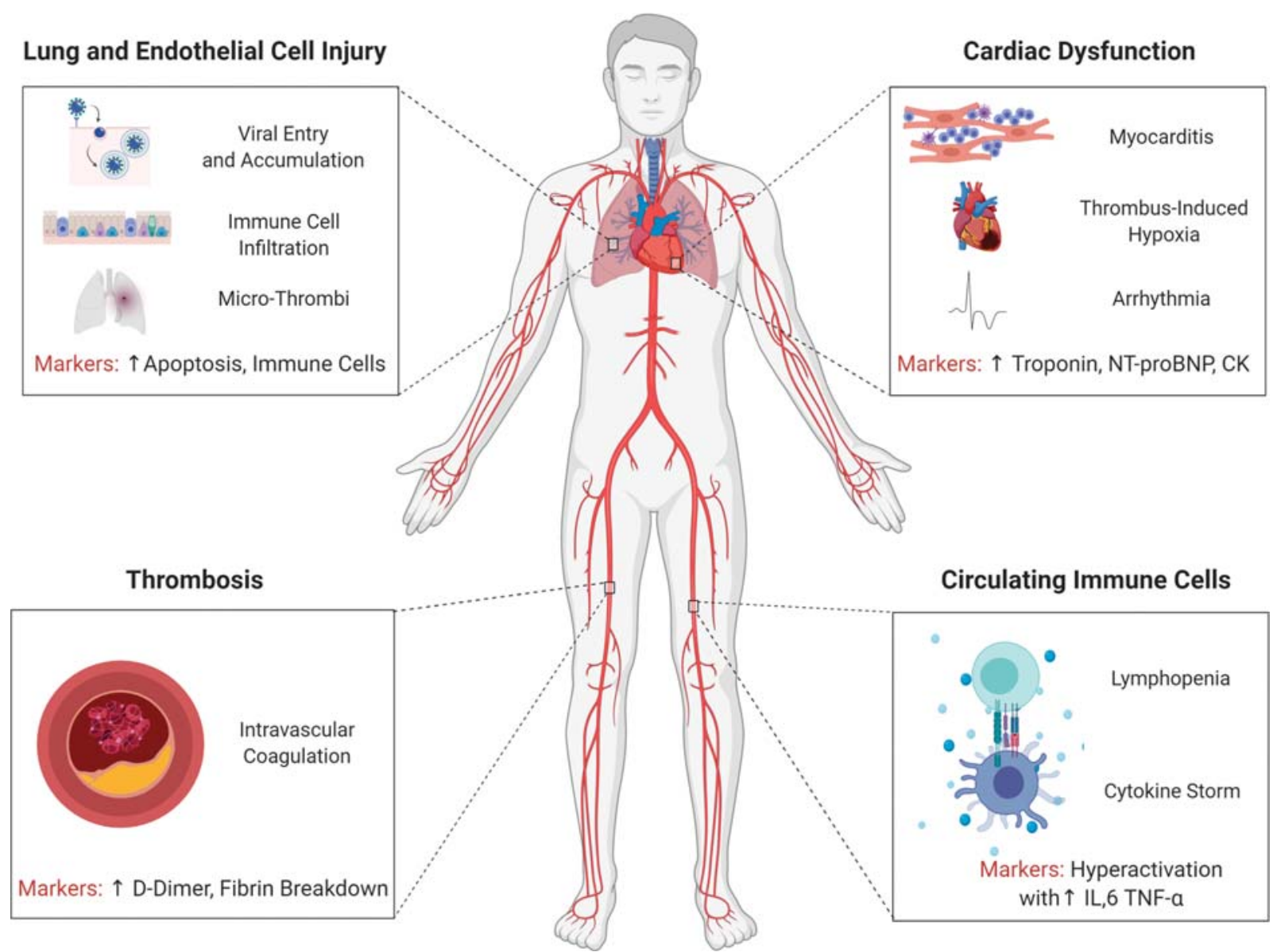

Fig. 1 Summary of systemic effects of SARS-CoV-2 infection on endothelial cells, immune cells, coagulation system, and cardiac inflammation. Viral infection first mediates endothelial dysfunction with observed changes in the RAAS system as well as inflammation, oxidative stress, upregulation of adhesion molecules for leukocyte recruitment, and intravascular coagulation leading toward microthrombi in the lungs. Inflammatory cytokine storms involving expression of macrophage IL-6 and TNF- $\alpha$ leading to hyperactivation and increased apoptosis of lymphocytes characterize systemic inflammation in severe COVID-19 patients. Ultimately, inflammation may be tied to both elevated levels of thrombosis and cardiac injury as observed in markers such as the D-dimer and troponin. Created with Biorender. CK, creatine kinase; IL-6, interleukin-6; NT-proBNP, NT-proB-type natriuretic peptide; RAAS, renin-angiotensin aldosterone system; TNF- $\alpha$ : tumor necrosis factor $\alpha$.

Interestingly, both chemokines control T cell migration, which may link them to both Th17-mediated lung and atherosclerotic inflammations. ${ }^{77-79}$

Outside of the lungs, significant lymphopenia in the blood is associated with severe infection. ${ }^{80,81}$ Flow cytometric analysis revealed that $\mathrm{T}$ cells from COVID-19 patients were hyperactivated with increased expression of human leukocyte antigenDR isotope (HLA-DR) and CD38. ${ }^{75}$ Furthermore, hyperactivated T cells from COVID-19 patients were shown to upregulate CD25 and IL-2 expression while Tregulatory-associated forehead box P3 (Foxp3) expression was downregulated, which may lead to unregulated $\mathrm{T}$ cell proliferation in response to SARS-CoV-2 infection. ${ }^{82}$ Clinical characteristics of COVID-19 patients reported cytokine storms with increased concentrations of several inflammatory cytokines including IL-2, IL-6, and TNF$\alpha^{17}$. Overactivation of proinflammatory Th17 and high cytotoxicity of CD8 + cells may help explain the severe lung injury presented in some COVID-19 patients. Although this cytokine storm may be in part attributed to T cells, several reports have noted a low level of interferon responses in COVID-19 patients suggesting SARS-CoV-2 has more distinct transcriptional response compared with other respiratory viruses. ${ }^{83,84}$

Macrophages, on the other hand, represent another likely source of the cytokine storm. The systemic cytokine profile observed in COVID-19 patients has been compared with macrophage activation syndrome (MAS), which is typically characterized by uncontrolled activation and expansion of both macrophages and $\mathrm{T}$ cells. ${ }^{85,86}$ In addition to resident lung macrophages, proinflammatory monocyte-derived macrophages appeared to be abundant in the bronchoalveolar fluid of COVID-19 patients. Interestingly, RNA-sequencing (RNA-seq) analysis of those macrophages revealed an upregulation of inflammatory cytokines including IL-1B and IL-6 as well as chemokine receptors such as CCL2 and CCL3 in severe COVID infections, which may suggest recruitment of inflammatory monocytic cells together with neutrophils. ${ }^{87}$ The hyperactivation of macrophages with its subsequent cytokine profile may account for the severe lymphopenia observed in COVID-19 patients as one study revealed increased expression of the death receptor FAS on T cells that could mediate activation-induced 
Table 2 Potential therapeutics for treating the hyperinflammation observed in severe COVID-19 patients

\begin{tabular}{|c|c|c|}
\hline Potential treatments & Targets and action & References \\
\hline \multirow[t]{4}{*}{ Anticoagulants } & $\begin{array}{l}\text { - Low-molecular-weight and unfractionated heparin as first line of treatment to prevent } \\
\text { thrombotic events through activation of antithrombin III }\end{array}$ & 112,113 \\
\hline & $\begin{array}{l}\text { - Heparin may have additional antiviral and anti-inflammatory properties that prevent } \\
\text { viral entry into cells by displacing surface proteoglycans including the } S \text { protein of } \\
\text { SARS-CoV-2 as well as prevention of vascular-occluding neutrophil extracellular traps }\end{array}$ & 89 \\
\hline & $\begin{array}{l}\text { - Danaparoid, typically prescribed to patients with thrombocytopenia and venous } \\
\text { thromboembolism, may be a secondary option which inhibits factor Xa and thrombin }\end{array}$ & 112,113 \\
\hline & $\begin{array}{l}\text { - Concentrated danaparoid dosage nebulized into the lungs may direct its effect toward } \\
\text { the lung, but no published reports exist for COVID-19 usage }\end{array}$ & 112 \\
\hline RAAS inhibitors & $\begin{array}{l}\text { - RAAS has been shown to drive inflammation through the angiotensin II-AT }{ }_{1} \text { axis. } \\
\text { Inhibitors of RAAS such as ACEis and ARBs interfere with the ACE2-driven angiotensin II } \\
\text { production and angiotensin II binding to its receptor, respectively. Therefore, RAAS } \\
\text { inhibitors may decrease RAAS-driven inflammation }\end{array}$ & 31,127 \\
\hline \multirow[t]{3}{*}{$\begin{array}{l}\text { Cytokine-blocking } \\
\text { therapies }\end{array}$} & $\begin{array}{l}\text { - Monoclonal antibody treatments targeting cytokines produced during the hyper- } \\
\text { inflammatory state in COVID-19 patients have been previously shown to reduce risk in } \\
\text { several diseases including atherosclerosis }\end{array}$ & 102,103 \\
\hline & $\begin{array}{l}\text { - The COVACTA trial which utilized tocilizumab to target the IL-6 receptor reported that } \\
\text { patient status and mortality were not improved after } 4 \text { weeks of treatment }\end{array}$ & 104,140 \\
\hline & $\begin{array}{l}\text { - Ongoing clinical trials are testing the effectiveness of IL-1 inhibition through the use of } \\
\text { high-dose anakinra and canakinumab }\end{array}$ & $103,141,142$ \\
\hline Corticosteroids & $\begin{array}{l}\text { - Systemic glucocorticoid treatment has been shown to reduce viral shedding in } \\
\text { previous SARS and MERS outbreaks on top of their known anti-inflammatory and } \\
\text { immunosuppressive effects } \\
\text { - The RECOVERY trial demonstrated a } 6 \mathrm{mg} \text { daily dosage of dexamethasone reduced the } \\
\text { 28-day mortality rate of patients receiving oxygen }\end{array}$ & 143,144 \\
\hline
\end{tabular}

Abbreviations: ACE2, angiotensin-converting enzyme-2; ACEi, ACE inhibitor; ARB, angiotensin II receptor blockers; $\mathrm{AT}_{1}$, angiotensin II receptor type I; IL, interleukin; MERS, Middle East respiratory syndrome; RAAS, renin-angiotensin aldosterone system; SARS, severe acute respiratory syndrome.

cell death. ${ }^{88}$ Recently, severe COVID-19 has been characterized by a highly pronounced formation and aggregation of neutrophil extracellular traps (NETs) inside microvessels, leading to rapid occlusion, disturbed microcirculation, and organ damage. Neutrophil granulocytes are strongly activated and adopt a lowdensity phenotype prone to spontaneously form NETs, and accordingly markers of NET turnover are increased in COVID19 and linked to disease severity. This process could potentially be targeted by heparin ( - Table 2 ). ${ }^{89}$

However, several studies have also reported increased $\mathrm{T}$ cell exhaustion in severe infections as noted by increased expression of programmed cell death protein 1 (PD-1) on $\mathrm{T}$ cells from COVID-19 patients, which might be a consequence of $\mathrm{T}$ cell hyperactivation that leads to lymphopenia. ${ }^{81,90}$ Postmortem autopsies revealed that SARS-CoV-2 infection resulted in increased apoptosis of T cells in lymph nodes and spleen, which may be mediated by direct infection though lymphocytic ACE2 expression, which is still questionable. $^{75,88}$ In recovering COVID-19 patients, single cell (sc) RNA-seq and T cell receptor sequencing (TCR-seq) revealed high levels of expression for inflammatory genes, but decreased $\mathrm{T}$ cell expansion compared with healthy controls further suggesting that $\mathrm{T}$ cell exhaustion plays an important role in SARS-CoV-2 infection. ${ }^{91}$

Importantly, inflammation from immune cells like T cells and macrophages plays a key role in CVDs such as atherosclerosis. Due to this inflammation, COVID-19 patients have a higher risk for cardiovascular manifestations including myocardial infarction and stroke. ${ }^{16,92} \mathrm{~A}$ link between acute infections and adverse cardiovascular events has been established, but the cytokine storm observed in severe COVID-19 patients may heighten the risk. ${ }^{93}$ Using hyperlipidemic mice models, previous research has established proatherogenic roles for inflammatory cytokines within the cytokine storm such as IL- 6 and TNF- $\alpha .^{94,95}$ Both cytokines are actively produced by innate and adaptive immune cells, possibly in response to initial complement cascades or innate immune cell inflammasome activation and subsequent IL- $1 \beta$ production $^{96-98}$ leading to microvascular injury and thrombotic microangiopathy in some patients with COVID-19 (- Fig. 1). Inflammasome activation has been previously linked to pyroptosis of macrophages and endothelial cells leading to massive thrombosis, which may be fundamental to understanding the unusual thrombosis risks associated with COVID-19.99,100

IL-1 $\beta$ activates endothelial cells during vascular inflammation to upregulate adhesion molecules allowing leukocytes to infiltrate and expand atherosclerotic lesions. Within the plaque, IL-1 $\beta$ induces collagenase, metalloproteinase, and cytokine expression leading to plaques that are more vulnerable to rupture. ${ }^{101}$ Plaque rupture leads to the activation of platelets and thrombosis formation, which may occlude the vessel lumen leading to potential cardiovascular complications. In humans, the Canakinumab Anti-Inflammatory Thrombosis Outcomes Study (CANTOS) demonstrated the ability of IL-1 $\beta$ 
inhibition to reduce adverse cardiac events. ${ }^{102,103}$ Although most studies have not reported an increase in IL-1 $\beta$ levels, IL-1 receptor blockade was associated with clinical improvement in COVID-19 patients without invasive ventilation. ${ }^{104}$ Similarly, IL-6 antagonism using tocilizumab has proven to be an effective treatment for severe infection. ${ }^{105}$ Considering several studies have reported hypercoagulable states in COVID-19 patients, further studies investigating a link between SARSCoV-2 infection, vascular inflammation, and atherothrombosis are needed.

\section{Thrombosis}

In severe COVID-19 cases, patients develop a type of ARDS, which is characterized by alveolar damage and fibrosis that may be due to the infiltration of immune cells and cytokines as mentioned previously. Fibrin deposition may be a consequence of the hyperactivation of macrophages and $\mathrm{T}$ cells during MAS, which leads to increased endothelial cell damage and diffuse lung injury. ${ }^{106}$ Supporting the inflammatory hypothesis for increased thrombosis, serum proteomic analysis revealed that elevated IL-6 was a critical marker for upregulation of coagulation markers including Factor 5, 7, and 10 in the most severe COVID-19 patients. ${ }^{107}$ Thromboelastometry measures may be beneficial to distinguish the difference in hypercoagulability of mild and severe cases as prolonged clot formation time and ThromboDynamic Index were reported in critically ill patients needing invasive ventilation. ${ }^{108}$ Ultimately, severe SARS-CoV-2 infection presents with pulmonary intravascular coagulation that appears to be similar to disseminated intravascular coagulation. ${ }^{106}$ Several studies observe consistent hematological parameters such as increased DDimer with moderate thrombocytopenia that support an increase in thrombus formation as well as the breakdown of fibrin products (-Fig. 1) $)^{4,9,109}$ Further complicating the issue, a small study comparing the clot lysis between control samples and COVID-19 samples described impaired lysis pointing to fibrinolytic resistance on top of the hypercoagulability during severe SARS-CoV-2 infection. ${ }^{110}$

When compared with influenza patients, COVID-19 patients had nine times as many alveolar capillary microthrombi leading to significant capillary occlusion. ${ }^{74}$ A series of autopsies found an interesting link between the increase in thrombosis and ACE2 expression. Thrombotic microangiopathy was not observed in tissues not expressing ACE2 such as vasculature of the kidneys; however, multiple thrombotic events were discovered in ACE2-expressing lung and brain parenchymal capillaries. ${ }^{111}$ Therapeutic anticoagulant treatment has been associated with decreased mortality in COVID-19 patients highlighting thrombosis as a critical turning point in SARS-CoV-2 infection. ${ }^{112}$ Specifically, lowmolecular-weight and unfractionated heparin has been proposed as the first line of treatment, which may possess both anti-inflammatory and antiviral properties via disrupting viral interaction with ACE2 (- Table 2). ${ }^{13,114}$ More targeted anticoagulant therapies, including inhaled danaparoid, may allow a directed approach to tailor treatment toward the thrombus-induced inflammation in the lungs. ${ }^{113}$
While microthrombi contribute to the development of respiratory dysfunction, they may also lead to multiorgan damage including cardiovascular complications such as heart failure. Lung injury due to increased thrombosis may induce pulmonary hypertension, which leads to observable increases in cardiac troponin, creatine kinase (CK), and N-terminal pro-B type natriuretic peptide levels in critically ill COVID-19 patients. ${ }^{6,11,18,115}$ Outcomes from an in-hospital study reported $32 \%$ of COVID-19 patients had heart failure. However, the numbers were skewed toward nonsurvivors when comparing nonsurvivors ( $52 \%$ heart failure) to survivors (12\% heart failure), suggesting heart failure may correlate with disease severity rather than infection itself. ${ }^{8}$ Similarly, in a cohort of 799 COVID-19 patients, heart failure was the second most common cause of death after ARDS. ${ }^{116}$ The combination of right ventricular heart failure together with lung fibrosis might contribute to decreased lung perfusion leading to a hypoxic state observed in severe cases. ${ }^{117}$ Interestingly, one postmortem study observed increased pulmonary angiogenesis in COVID-19 patients, suggesting new vessel growth was necessary for accurate lung perfusion. ${ }^{74}$ Furthermore, arterial or venous thrombosis accounted for $16.4 \%$ of COVID-19 hospital readmissions in a cohort of 1,368 patients likely influencing ischemic conditions in severe cases. ${ }^{118}$ Preexisting cardiovascular comorbidities including hypertension and diabetes were associated with COVID-19 case severity, which likely exacerbate heart failure and other cardiac injuries. ${ }^{4,17,19}$

\section{Cardiac Injury}

Although heart failure represents one side of the cardiac injury involved in SARS-CoV-2 infection, several studies have also reported cardiac arrhythmia and myocarditis in COVID19 patients. A retrospective study identified the heart was the earliest damaged tissue after the lungs following SARSCoV-2 infection. ${ }^{119}$ While most studies have not investigated specific arrhythmias, one report observed arrhythmic complication in $16.7 \%$ of COVID-19 patients, making it the most common complication after ARDS (-Fig. 1). ${ }^{18}$ Furthermore, arrhythmias may manifest in more severe cases as one report found arrhythmias more often in patients admitted to an intensive care unit. ${ }^{18}$ Thrombus-induced hypoxia or inflammation may in part explain the high prevalence of arrhythmias in COVID-19 patients especially those with preexisting cardiovascular risk factors. ${ }^{120}$ However, elevated cardiac troponin and CK levels may indicate an underlying myocardial inflammation considering irregular ventricular arrhythmias can be associated with myocarditis. ${ }^{121,122}$

To date, there is limited clinical evidence of myocarditis with only a few case reports in COVID-19 patients all with varying degrees of myocardial inflammation ( - Fig. 1)., ,, $123-125^{-125}$ However, the mechanism behind this cardiac injury in COVID19 remains unclear particularly as a primary or secondary effect of SARS-CoV-2 infection. Interestingly, the receptor for viral entry, ACE2, is expressed in pericytes of the cardiovascular system, and its expression appears to be upregulated in failing hearts. ${ }^{24}$ Additionally, single-cell RNA sequencing revealed that cardiomyocytes also express ACE2, which was 
upregulated in patients receiving ACEis for pre-existing cardiovascular conditions. ${ }^{25}$ However, COVID-19 patients present acute cardiac injury symptoms on average 15 days after the onset of symptoms suggesting direct infection may not be the likely cause of myocardial inflammation., ${ }^{8,126}$ A secondary immune-mediated effect of SARS-CoV-2 might be the more likely explanation considering the timeline of symptoms. Particularly, inflammatory hyperactivation, as observed by the cytokine storm, and subsequent increase in inflammatory biomarkers have been associated with myocardial damage and cardiac injury. ${ }^{11,127}$ To distinguish the cardiac injury mechanisms at play in SARS-CoV-2 infection, further investigation requires a systematic elevation of larger cohorts of severe COVID-19 cases as well as experimental work using both in vitro and in vivo models.

\section{Outlook for Targeting SARS-CoV-2 Inflammation}

Hyperinflammation appears to be a common theme in the immunomodulatory, thrombotic, and cardiovascular complications associated with SARS-CoV-2 infection. Therefore, a variety of anti-inflammatory treatments have been purposed for severe COVID-19, including RAAS inhibitors, cytokineblocking therapies, and corticosteroids. However, preliminary evidence for each therapy demonstrates both advantages and disadvantages depending on their target.

Inhibitors of RAAS, such as ACEis and ARBs, are widely used to treat hypertension. In the context of atherosclerosis, these inhibitors were also shown to be effective in suppressing inflammation as well as oxidative stress (-Table 2). ${ }^{128}$ The use of RAAS blockers in COVID-19 patients, however, has caused a great dilemma among health care workers, due to their probable impact on ACE2-SARS-CoV-2 dynamics. ${ }^{129-131}$ Keidar and colleagues showed that mineralocorticoid receptor blockade via spironolactone, aimed at hindering the activity of aldosterone, increased ACE2 expression and activity in monocyte-derived macrophages collected from patients with congestive heart failure. ${ }^{132}$ Another study showed that an ARB named telmisartan reduced ACE2 levels in the aorta of spontaneous hypertensive rats. ${ }^{133}$ Moreover, Ferrario and colleagues revealed that the treatment of Lewis rats with angiotensin II receptor antagonist losartan increased cardiac messenger RNA (mRNA) levels and activity of ACE2. ${ }^{134}$ In view of that, RAAS inhibitor-related ACE2 upregulation has been hypothesized by several scientists to increase the risk and incidence of SARS-CoV-2 infection as there would be theoretically more doorways available for the virus entry. ${ }^{135}$ Moreover, there is no scientific evidence to support the theoretical concern that RAAS ${ }^{136}$ blockers may increase the threat or severity of the SARS-CoV-2 infection. Meanwhile, Milne and colleagues tested mRNA expression levels of ACE2 in human lung tissues upon ACEi and ARB treatments and disclosed a decrease in ACE2 levels via ACEi treatment whereas ARB treatment did not cause any differences. ${ }^{137}$

Of note, several studies investigating the association between the risk of SARS-CoV-2 infection and the use of RAAS inhibitors disclosed that RAAS inhibitors do not impose an increased risk of viral infection. Mancia and colleagues reported no association between the use of ACEi and ARB and COVID-19 in a case-control study in Lombardy, Italy with a total of 6,272 cases and 30,759 matched controls. ${ }^{138}$ Another study in New York City, United States evaluating the connection between the likelihood of testing positive for COVID-19 as well as the severity of the disease and the use of RAAS inhibitors among other treatments, such as $\beta$-blockers and calcium-channel blockers, disclosed no association between any of these treatments and the risk of infection as well as the disease severity. ${ }^{139}$ Finally, another study by Mehra and colleagues with a database from 169 hospitals in Asia, Europe, and North America reported that underlying CVDs are indeed associated with an increased risk of death among the hospitalized COVID-19 patients, whereas ACEi and ARB treatment was not associated with in-hospital death. ${ }^{59}$

It seems, regardless of its amount, the presence of ACE2 is sufficient to support virus entry and a decrease of the receptor activity empowers the severity of the illness due to the abolished protective roles of ACE2. In this case, targeting increased activity of ACE2 may be of benefit rather than a disadvantage to restrict the impact of the COVID-19, both for the pulmonary and cardiovascular systems. ${ }^{140}$ Besides, COVID-19 has been shown to cause a strong inflammatory response in patients, leading to a so-called cytokine storm, which also strongly contributes to an ARDS. ${ }^{17}$ This rise in inflammation further feeds chronic inflammatory diseases, such as atherosclerosis, and therefore worsens the patients' prognosis. The immunomodulatory benefit of the ACE2-angiotensin (1-7)-Mas axis contrasting the proinflammatory role of RAAS is especially advantageous with regard to the management of the inflammation and therefore the manifestations of chronic inflammatory diseases.

The massive immune response observed during SARS$\mathrm{CoV}-2$ infection has prompted a search for therapeutics primarily targeting the inflammatory cytokine storm. Unlike broad immunosuppression, cytokine-blocking therapies such as those targeting IL- 6 and IL- $1 \beta$ likely should not dampen the host's response to the virus. While initial reports of IL-6R antagonists were promising, the results from phase III of the COVACTA trial recently announced that tocilizumab did not meet its primary endpoint of improved clinical status of COVID-19 patients ( - Table 2). ${ }^{104,141}$ Nevertheless, clinical trials are still pursuing the clinical relevance of other cytokine-blocking therapies including IL-1 $\beta$ inhibition using anakinra and canakinumab ( - Table 2). ${ }^{142,143}$

A recent breakthrough heralded in a press release only at the time of submission may provide further evidence of a more global role of excessive inflammation and the importance of its control in COVID-19. The randomized controlled RECOVERY trial enrolled 2,100 patients who received a low dose of the corticosteroid dexamethasone for 10 days, and compared them against 4,300 patients who received standard care. The results revealed a striking effect of dexamethasone among critically ill patients on ventilators and those receiving oxygen therapy, reducing their mortality by up to $30 \%$ (-Table 2). ${ }^{144}$ Dexamethasone is a type of glucocorticoid, which are known to exert potent anti-inflammatory 
effects and are therefore used in the treatment of several autoimmune and inflammatory diseases such as asthma and ulcerative colitis. ${ }^{145}$ Therefore, glucocorticoids may be very useful in the treatment of heightened immune response to COVID-19, including the cytokine storms. Moreover, dexamethasone treatment might potentially offer further benefits to patients besides immunosuppression. Despite the association of glucocorticoids with venous thromboembolism, ${ }^{146}$ a study by van Giezen et al investigating hemostatic effects of dexamethasone on rats showed a twofold decrease in arterial thrombosis and reduced platelet aggregation with low-dose treatments (up to $1 \mathrm{mg} / \mathrm{kg}$ ). ${ }^{147}$ It is important to note, however, that higher doses of dexamethasone (from $1 \mathrm{mg} / \mathrm{kg}$ onwards) yielded a decrease in fibrinolytic activity and counteracted the arterial thrombosis. Further research is needed to explore such potential benefits of dexamethasone as well as its dose-dependent effects.

Without a doubt, COVID-19 presents an immense challenge for the health care system due to its wide-ranging impact on the health of diverse groups of patients. Although severe COVID-19 cases typically present with similar thrombotic and inflammatory characteristics, data describing the most representative biomarkers are still evolving. Therefore, future treatments for thromboinflammation may need to be tailored to better fit the patients' individual needs. ${ }^{148}$ The safety of the drugs intended to treat COVID-19 patients should be carefully considered, especially for those with underlying health problems, such as CVDs. Larger studies investigating these drugs in the context of CVDs are needed to identify groups of patients who are at higher risk for suffering from serious and even lethal consequences of these treatments.

\section{Conclusion}

In this review, we aimed to highlight the immunoinflammatory mechanisms and subsequent thrombohemostatic and cardiovascular effects of COVID-19 especially in patients with underlying cardiovascular risk factors. Considering the novel nature of the virus, our knowledge is still growing with regard to the systemic and local effects of SARS-CoV-2 infection. With this in mind, many questions remain unanswered about the primary and secondary causes of the cardiovascular manifestations of COVID-19 patients. In the upcoming months, systematic analyses of larger patient cohorts, in particular at a genome-wide genetic level, are needed to dissect and explain differential predisposition in different blood groups and ethnicities. Together with experimental work, researchers may be able to shed more light on the identification of the underlying mechanisms of inflammation, thrombosis, and cardiac injury in COVID-19 patients. ${ }^{79}$ In the meantime, careful evaluation of new therapeutics for SARS-CoV-2 should highlight their effects on the cardiovascular system as many studies have observed cardiovascular complications ranging from ischemic stroke to myocarditis in severe cases especially with hypertensive and diabetic patients. Considering we have seen several similar coronaviruses in the past, careful and thorough research in SARS-CoV-2 will likely improve our understanding of future coronaviruses.
Funding

This study was supported by Deutsche Forschungsgemeinschaft (SFB1123).

\section{Conflict of Interest}

None declared.

\section{Acknowledgments}

We thank Dr. Donato Santovito (IPEK, LMU Munich) for his suggestions and review of the manuscript.

\section{References}

1 Dong E, Du H, Gardner L. An interactive web-based dashboard to track COVID-19 in real time. Lancet Infect Dis 2020;20(05): 533-534

2 Wu Z, McGoogan JM. Characteristics of and important lessons from the Coronavirus Disease 2019 (COVID-19) outbreak in China: summary of a report of 72314 cases from the Chinese Center for Disease Control and Prevention. JAMA 2020;323(13): 1239-1242

3 Cheng VCC, Lau SKP, Woo PCY, Yuen KY. Severe acute respiratory syndrome coronavirus as an agent of emerging and reemerging infection. Clin Microbiol Rev 2007;20(04):660-694

4 Guan WJ, Ni ZY, Hu Y, et al; China Medical Treatment Expert Group for Covid-19. Clinical characteristics of coronavirus disease 2019 in China. N Engl J Med 2020;382(18):1708-1720

5 Lovato A, de Filippis C. Clinical presentation of COVID-19: a systematic review focusing on upper airway symptoms. Ear Nose Throat J 2020. Doi: 10.1177/0145561320920762

6 Inciardi RM, Lupi L, Zaccone G, et al. Cardiac involvement in a patient with coronavirus disease 2019 (COVID-19). JAMA Cardiol 2020;5(07):819-824

7 Sala S, Peretto G, Gramegna M, et al. Acute myocarditis presenting as a reverse Tako-Tsubo syndrome in a patient with SARS-CoV-2 respiratory infection. Eur Heart J 2020;41(19): $1861-1862$

8 Zhou F, Yu T, Du R, et al. Clinical course and risk factors for mortality of adult inpatients with COVID-19 in Wuhan, China: a retrospective cohort study. Lancet 2020;395(10229):1054-1062

9 Lippi G, Favaloro EJ. D-dimer is associated with severity of coronavirus disease 2019: a pooled analysis. Thromb Haemost 2020;120(05):876-878

10 Danzi GB, Loffi M, Galeazzi G, Gherbesi E. Acute pulmonary embolism and COVID-19 pneumonia: a random association? Eur Heart J 2020;41(19):1858

11 Shi S, Qin M, Shen B, et al. Association of cardiac injury with mortality in hospitalized patients with COVID-19 in Wuhan, China. JAMA Cardiol 2020;5(07):802-810

12 Cowan LT, Lutsey PL, Pankow JS, Matsushita K, Ishigami J, Lakshminarayan K. Inpatient and outpatient infection as a trigger of cardiovascular disease: the ARIC study. J Am Heart Assoc 2018;7(22):e009683

13 Madjid M, Miller CC, Zarubaev VV, et al. Influenza epidemics and acute respiratory disease activity are associated with a surge in autopsy-confirmed coronary heart disease death: results from 8 years of autopsies in 34,892 subjects. Eur Heart J 2007;28(10): $1205-1210$

14 Peiris JSM, Chu CM, Cheng VCC, et al; HKU/UCH SARS Study Group. Clinical progression and viral load in a community outbreak of coronavirus-associated SARS pneumonia: a prospective study. Lancet 2003;361(9371):1767-1772

15 Chong PY, Chui P, Ling AE, et al. Analysis of deaths during the severe acute respiratory syndrome (SARS) epidemic in Singapore: challenges in determining a SARS diagnosis. Arch Pathol Lab Med 2004;128(02):195-204 
16 Merkler AE, Parikh NS, Mir S, et al. Risk of ischemic stroke in patients with Covid-19 versus patients with influenza. medRxiv 2020. Doi: $10.1101 / 2020.05 .18 .20105494$

17 Huang C, Wang Y, Li X, et al. Clinical features of patients infected with 2019 novel coronavirus in Wuhan, China. Lancet 2020;395 (10223):497-506

18 Wang D, Hu B, Hu C, et al. Clinical characteristics of 138 hospitalized patients with 2019 novel coronavirus-infected pneumonia in Wuhan, China. JAMA 2020;323(11):1061-1069

19 Zhu L, She ZG, Cheng X, et al. Association of blood glucose control and outcomes in patients with COVID-19 and pre-existing type 2 diabetes. Cell Metab 2020;31(06):1068.e3-1077.e3

20 Hoffmann M, Kleine-Weber H, Schroeder S, et al. SARS-CoV-2 cell entry depends on ACE2 and TMPRSS2 and is blocked by a clinically proven protease inhibitor. Cell 2020;181(02):271. e8-280.e8

21 Lu R, Zhao X, Li J, et al. Genomic characterisation and epidemiology of 2019 novel coronavirus: implications for virus origins and receptor binding. Lancet 2020;395(10224):565574

22 Renhong Y, Yuanyuan Z, Yaning L, Lu X, Yingyang G, Qlang Z. Structural basis for the recognition of SARS-CoV-2 by full-length human ACE2. Science 2020;367(6485):1444-1448

23 Li MY, Li L, Zhang Y, Wang XS. Expression of the SARS-CoV-2 cell receptor gene ACE2 in a wide variety of human tissues. Infect Dis Poverty 2020;9(01):45

24 Chen L, Li X, Chen M, Feng Y, Xiong C. The ACE2 expression in human heart indicates new potential mechanism of heart injury among patients infected with SARS-CoV-2. Cardiovasc Res 2020; 116(06):1097-1100

25 Nicin L, Abplanalp WT, Mellentin H, et al. Cell type-specific expression of the putative SARS-CoV-2 receptor ACE2 in human hearts. Eur Heart J 2020;41(19):1804-1806

26 Fountain J, Lappin S. Physiology, Renin Angiotensin System. [Updated July 27, 2020]. In: StatPearls [Internet]. Treasure Island, FL: StatPearls Publishing

27 Ma TKW, Kam KKH, Yan BP, Lam YY. Renin-angiotensin-aldosterone system blockade for cardiovascular diseases: current status. Br J Pharmacol 2010;160(06):1273-1292

$28 \mathrm{Wu} \mathrm{CH}$, Mohammadmoradi S, Chen JZ, Sawada H, Daugherty A, Lu HS. Renin-angiotensin system and cardiovascular functions. Arterioscler Thromb Vasc Biol 2018;38(07):e108-e116

29 Rüster C, Wolf G. Renin-angiotensin-aldosterone system and progression of renal disease. J Am Soc Nephrol 2006;17(11): 2985-2991

$30 \mathrm{Cohn}$ JN. Role of the renin-angiotensin system in cardiovascular disease. Cardiovasc Drugs Ther 2010;24(04):341-344

31 Ruiz-Ortega M, Lorenzo O, Rupérez M, et al. Role of the reninangiotensin system in vascular diseases: expanding the field. Hypertension 2001;38(06):1382-1387

32 Underwood PC, Adler GK. The renin angiotensin aldosterone system and insulin resistance in humans. Curr Hypertens Rep 2013;15(01):59-70

33 Favre GA, Esnault VLM, Van Obberghen E. Modulation of glucose metabolism by the renin-angiotensin-aldosterone system. Am J Physiol Endocrinol Metab 2015;308(06):E435-E449

34 Umemura S, Nyui N, Tamura K, et al. Plasma angiotensinogen concentrations in obese patients. Am J Hypertens 1997;10(06): 629-633

35 Sharma AM, Engeli S. Obesity and the renin- angiotensin-aldosterone system. Expert Rev Endocrinol Metab 2006;1(02): 255-264

36 Schütten MTJ, Houben AJHM, de Leeuw PW, Stehouwer CDA. The link between adipose tissue renin-angiotensin-aldosterone system signaling and obesity-associated hypertension. Physiology (Bethesda) 2017;32(03):197-209

37 Dorresteijn JAN, Visseren FLJ, Spiering W. Mechanisms linking obesity to hypertension. Obes Rev 2012;13(01):17-26
38 Goodfriend TL, Egan BM, Kelley DE. Aldosterone in obesity. In: Endocrine Research. Vol 24;New York, NY: Marcel Dekker Inc.; 1998:789-796

39 Frigolet ME, Torres N, Tovar AR. The renin-angiotensin system in adipose tissue and its metabolic consequences during obesity. J Nutr Biochem 2013;24(12):2003-2015

40 Carroll WX, Kalupahana NS, Booker SL, et al. Angiotensinogen gene silencing reduces markers of lipid accumulation and inflammation in cultured adipocytes. Front Endocrinol (Lausanne) 2013;4:10

41 Gheblawi M, Wang K, Viveiros A, et al. Angiotensin-converting enzyme 2: SARS-CoV-2 receptor and regulator of the reninangiotensin system: celebrating the 20th anniversary of the discovery of ACE2. Circ Res 2020;126(10):1456-1474

42 Dalan R, Bornstein SR, El-Armouche A, et al. The ACE-2 in COVID19: foe or friend? Horm Metab Res 2020;52(05):257-263

43 Echeverría-Rodríguez O, Del Valle-Mondragón L, Hong E. Angiotensin 1-7 improves insulin sensitivity by increasing skeletal muscle glucose uptake in vivo. Peptides 2014;51:26-30

44 Passos-Silva DG, Verano-Braga T, Santos RAS. Angiotensin-(1-7): beyond the cardio-renal actions. Clin Sci (Lond) 2013;124(07): 443-456

45 Meng Y, Yu CH, Li W, et al. Angiotensin-converting enzyme 2/ angiotensin-(1-7)/Mas axis protects against lung fibrosis by inhibiting the MAPK/NF-KB pathway. Am J Respir Cell Mol Biol 2014;50(04):723-736

46 Rodrigues Prestes TR, Rocha NP, Miranda AS, Teixeira AL, SimoesE-Silva AC. The anti-inflammatory potential of ACE2/angiotensin-(1-7)/Mas receptor axis: evidence from basic and clinical research. Curr Drug Targets 2017;18(11):1301-1313

47 Tseng YH, Yang RC, Lu TS. Two hits to the renin-angiotensin system may play a key role in severe COVID-19. Kaohsiung J Med Sci 2020;36(06):389-392

48 Wang Q, Zhang Y, Wu L, et al. Structural and functional basis of SARS-CoV-2 entry by using human ACE2. Cell 2020;181(04): 894-904.e9

49 Ou X, Liu Y, Lei X, et al. Characterization of spike glycoprotein of SARS-CoV-2 on virus entry and its immune cross-reactivity with SARS-CoV. Nat Commun 2020;11(01):1620

50 Satarker S, Nampoothiri M. Structural proteins in severe acute respiratory syndrome coronavirus-2. Arch Med Res 2020;51 (06):482-491

51 Shang J, Wan Y, Luo C, et al. Cell entry mechanisms of SARS-CoV2. Proc Natl Acad Sci U S A 2020;117(21):11727-11734

52 Aimes RT, Zijlstra A, Hooper JD, et al. Endothelial cell serine proteases expressed during vascular morphogenesis and angiogenesis. Thromb Haemost 2003;89(03):561-572

53 Imai Y, Kuba K, Penninger JM. The discovery of angiotensinconverting enzyme 2 and its role in acute lung injury in mice. Exp Physiol 2008;93(05):543-548

54 Kuba K, Imai Y, Rao S, et al. A crucial role of angiotensin converting enzyme 2 (ACE2) in SARS coronavirus-induced lung injury. Nat Med 2005;11(08):875-879

55 Zhong J, Basu R, Guo D, et al. Angiotensin-converting enzyme 2 suppresses pathological hypertrophy, myocardial fibrosis, and cardiac dysfunction. Circulation 2010;122(07):717-728

56 South AM, Diz DI, Chappell MC. COVID-19, ACE2, and the cardiovascular consequences. Am J Physiol Heart Circ Physiol 2020;318(05):H1084-H1090

57 Wang K, Gheblawi M, Oudit GY. Angiotensin converting enzyme 2: a double-edged sword. Circulation 2020. Doi: 10.1161/circulationaha.120.047049

58 Verdecchia P, Cavallini C, Spanevello A, Angeli F. The pivotal link between ACE2 deficiency and SARS-CoV-2 infection. Eur J Intern Med 2020;76:14-20

59 Mehra MR, Desai SS, Kuy S, Henry TD, Patel AN. Cardiovascular disease, drug therapy, and mortality in Covid-19. N Engl J Med 2020;382(25):e102 
60 Farah C, Michel LYM, Balligand JL. Nitric oxide signalling in cardiovascular health and disease. Nat Rev Cardiol 2018;15(05):292-316

61 Kim DH, Meza CA, Clarke H, Kim JS, Hickner RC. Vitamin D and endothelial function. Nutrients 2020;12(02):1-17

62 Cyr AR, Huckaby LV, Shiva SS, Zuckerbraun BS. Nitric oxide and endothelial dysfunction. Crit Care Clin 2020;36(02):307-321

63 Varga Z, Flammer AJ, Steiger P, et al. Endothelial cell infection and endotheliitis in COVID-19. Lancet 2020;395(10234):1417-1418

64 Asadi-Pooya AA, Simani L. Central nervous system manifestations of COVID-19: A systematic review. J Neurol Sci 2020; 413:116832

65 Castro Dias M, Mapunda JA, Vladymyrov M, Engelhardt B. Structure and junctional complexes of endothelial, epithelial and glial brain barriers. Int J Mol Sci 2019;20(21):5372

66 Wang K, Chen W, Zhou Y-S, et al. SARS-CoV-2 invades host cells via a novel route: CD147-spike protein. bioRxiv 2020. Doi: 10.1101/2020.03.14.988345

67 Yetik-Anacak G, Catravas JD. Nitric oxide and the endothelium: history and impact on cardiovascular disease. Vascul Pharmacol 2006;45(05):268-276

68 Desouza C, Parulkar A, Lumpkin D, Akers D, Fonseca VA. Acute and prolonged effects of sildenafil on brachial artery flowmediated dilatation in type 2 diabetes. Diabetes Care 2002;25 (08):1336-1339

69 Katz SD, Balidemaj K, Homma S, Wu H, Wang J, Maybaum S. Acute type 5 phosphodiesterase inhibition with sildenafil enhances flow-mediated vasodilation in patients with chronic heart failure. J Am Coll Cardiol 2000;36(03):845-851

70 Akerström S, Gunalan V, Keng CT, Tan YJ, Mirazimi A. Dual effect of nitric oxide on SARS-CoV replication: viral RNA production and palmitoylation of the S protein are affected. Virology 2009; 395(01):1-9

71 Saura M, Zaragoza C, McMillan A, et al. An antiviral mechanism of nitric oxide: inhibition of a viral protease. Immunity 1999;10 (01):21-28

72 Green SJ. Covid-19 accelerates endothelial dysfunction and nitric oxide deficiency. Microbes Infect 2020;22(4-5):149-150

73 Santovito D, Egea V, Bidzhekov K, et al. Noncanonical inhibition of caspase-3 by a nuclear microRNA confers endothelial protection by autophagy in atherosclerosis. Sci Transl Med 2020;12 (546):1-16

74 Ackermann M, Verleden SE, Kuehnel M, et al. Pulmonary vascular endothelialitis, thrombosis, and angiogenesis in Covid-19. N Engl J Med 2020;383(02):120-128

75 Xu Z, Shi L, Wang Y, et al. Pathological findings of COVID-19 associated with acute respiratory distress syndrome. Lancet Respir Med 2020;8(04):420-422

76 Ellinghaus D, Degenhardt F, Bujanda L, et al; Severe Covid-19 GWAS Group. Genomewide association study of severe Covid-19 with respiratory failure. N Engl J Med 2020. Doi: 10.1056/NEJMoa2020283

77 Abd Alla J, Langer A, Elzahwy SS, Arman-Kalcek G, Streichert T, Quitterer U. Angiotensin-converting enzyme inhibition downregulates the pro-atherogenic chemokine receptor 9 (CCR9)chemokine ligand 25 (CCL25) axis. J Biol Chem 2010;285(30): 23496-23505

78 Butcher MJ, Wu CI, Waseem T, Galkina EV. CXCR6 regulates the recruitment of pro-inflammatory IL-17A-producing T cells into atherosclerotic aortas. Int Immunol 2016;28(05):255-261

79 Wein AN, McMaster SR, Takamura S, et al. CXCR6 regulates localization of tissue-resident memory CD8 T cells to the airways. J Exp Med 2019;216(12):2748-2762

80 Tan L, Wang Q Zhang D, et al. Lymphopenia predicts disease severity of COVID-19: a descriptive and predictive study. Signal Transduct Target Ther 2020;5(01):33

81 Diao B, Wang C, Tan Y, et al. Reduction and functional exhaustion of T cells in patients with coronavirus disease 2019 (COVID-19). Front Immunol 2020;11:827
82 Kalfaoglu B, Almeida-Santos J, Tye CA, Satou Y, Ono M. T-cell hyperactivation and paralysis in severe COVID-19 infection revealed by single-cell analysis. bioRxiv 2020. Doi: 10.1101/ 2020.05.26.115923

83 Blanco-Melo D, Nilsson-Payant BE, Liu WC, et al. Imbalanced host response to SARS-CoV-2 drives development of COVID-19. Cell 2020;181(05):1036.e9-1045.e9

84 Hadjadj J, Yatim N, Barnabei L, et al. Impaired type I interferon activity and exacerbated inflammatory responses in severe Covid19 patients. medRxiv 2020. Doi: 10.1101/2020.04.19.20068015

85 McGonagle D, Sharif K, O'Regan A, Bridgewood C. The role of cytokines including interleukin-6 in COVID-19 induced pneumonia and macrophage activation syndrome-like disease. Autoimmun Rev 2020;19(06):102537

86 Crayne CB, Albeituni S, Nichols KE, Cron RQ. The immunology of macrophage activation syndrome. Front Immunol 2019;10:119

87 Liao M, Liu Y, Yuan J, et al. Single-cell landscape of bronchoalveolar immune cells in patients with COVID-19. Nat Med 2020; 26(06):842-844

88 Feng Z, Diao B, Wang R, et al. The novel severe acute respiratory syndrome coronavirus 2 (SARS-CoV-2) directly decimates human spleens and lymph nodes. medRxiv 2020;2:2020.03.27.20045427. Doi: 10.1101/2020.03.27.20045427

89 Leppkes M, Knopf J, Naschberger E, et al. Vascular occlusion by neutrophil extracellular traps in COVID-19. EBioMedicine 2020; 58:102925

90 Zheng HY, Zhang M, Yang CX, et al. Elevated exhaustion levels and reduced functional diversity of $\mathrm{T}$ cells in peripheral blood may predict severe progression in COVID-19 patients. Cell Mol Immunol 2020;17(05):541-543

91 Wen W, Su W, Tang H, et al. Immune cell profiling of COVID-19 patients in the recovery stage by single-cell sequencing. Cell Discov 2020;6(01):31

92 Lala A, Johnson KW, Januzzi J, et al. Prevalence and impact of myocardial injury in patients hospitalized with COVID- 19 infection. medRxiv 2020. Doi: 10.1101/2020.04.20.20072702

93 Smeeth L, Thomas SL, Hall AJ, Hubbard R, Farrington P, Vallance P. Risk of myocardial infarction and stroke after acute infection or vaccination. N Engl J Med 2004;351(25):2611-2618

94 Schieffer B, Selle T, Hilfiker A, et al. Impact of interleukin-6 on plaque development and morphology in experimental atherosclerosis. Circulation 2004;110(22):3493-3500

95 Brånén L, Hovgaard L, Nitulescu M, Bengtsson E, Nilsson J, Jovinge $S$. Inhibition of tumor necrosis factor- $\alpha$ reduces atherosclerosis in apolipoprotein E knockout mice. Arterioscler Thromb Vasc Biol 2004;24(11):2137-2142

96 Magro C, Mulvey JJ, Berlin D, et al. Complement associated microvascular injury and thrombosis in the pathogenesis of severe COVID-19 infection: a report of five cases. Transl Res 2020;220(June):1-13

97 Viedt C, Hänsch GM, Brandes RP, Kübler W, Kreuzer J. The terminal complement complex C5b-9 stimulates interleukin-6 production in human smooth muscle cells through activation of transcription factors NF-K B and AP-1. FASEB J 2000;14(15):2370-2372

98 Kang MJ, Jo SG, Kim DJ, Park JH. NLRP3 inflammasome mediates interleukin- $1 \beta$ production in immune cells in response to Acinetobacter baumannii and contributes to pulmonary inflammation in mice. Immunology 2017;150(04):495-505

$99 \mathrm{Wu} \mathrm{C}$, Lu W, Zhang Y, et al. Inflammasome activation triggers blood clotting and host death through pyroptosis. Immunity 2019;50(06):1401.e4-1411.e4

100 Jia C, Zhang J, Chen H, et al. Endothelial cell pyroptosis plays an important role in Kawasaki disease via HMGB1/RAGE/cathespin B signaling pathway and NLRP3 inflammasome activation. Cell Death Dis 2019;10(10):778

101 Libby P. Interleukin-1 beta as a target for atherosclerosis therapy: biological basis of CANTOS and beyond. J Am Coll Cardiol 2017; 70(18):2278-2289 
102 Ridker PM, Everett BM, Thuren T, et al. Antiinflammatory therapy with canakinumab for atherosclerotic disease. $\mathrm{N}$ Engl J Med 2017;377(12):1119-1131

103 Weber C, von Hundelshausen P. CANTOS trial validates the inflammatory pathogenesis of atherosclerosis: setting the stage for a new chapter in therapeutic targeting. Circ Res 2017;121 (10):1119-1121

104 Cavalli G, De Luca G, Campochiaro C, et al. Interleukin-1 blockade with high-dose anakinra in patients with COVID-19, acute respiratory distress syndrome, and hyperinflammation: a retrospective cohort study. Lancet Rheumatol 2020;2(06):e325-e331

105 Xu X, Han M, Li T, et al. Effective treatment of severe COVID-19 patients with tocilizumab. Proc Natl Acad Sci U S A 2020;117 (20):10970-10975

106 McGonagle D, O'Donnell JS, Sharif K, Emery P, Bridgewood C. Immune mechanisms of pulmonary intravascular coagulopathy in COVID-19 pneumonia. Lancet Rheumatol 2020;2(07): e437-e445

107 Alessandro A, Thomas T, Dzieciatkowska M, et al. Serum proteomics in COVID-19 patients: Altered coagulation and complement status as a function of IL-6 level. medRxiv 2020. Doi: 10.1101/ 2020.05.29.20116889

108 Boscolo A, Spiezia L, Correale C, et al. Different hypercoagulable profiles in patients with COVID-19 admitted to the internal medicine ward and the intensive care unit. Thromb Haemost 2020;120(10):1474-1477

109 Lippi G, Plebani M, Henry BM. Thrombocytopenia is associated with severe coronavirus disease 2019 (COVID-19) infections: A meta-analysis. Clin Chim Acta 2020;506:145-148

110 Weiss E, Roux O, Moyer J-D, et al. Fibrinolysis resistance: a potential mechanism underlying COVID-19 coagulopathy. Thromb Haemost 2020;120(09):1343-1345

111 Bryce C, Grimes Z, Pujadas E, et al. Pathophysiology of SARS-CoV2: targeting of endothelial cells renders a complex disease with thrombotic microangiopathy and aberrant immune response. The Mount Sinai COVID-19 autopsy experience. medRxiv 2020. Doi: $10.1101 / 2020.05 .18 .20099960$

112 Trinh M, Chang DR, Govindarajulu US, et al. Therapeutic anticoagulation is associated with decreased mortality in mechanically ventilated COVID-19 patients. medRxiv 2020:2020.05.30.20117929. Doi: 10.1101/2020.05.30.20117929

113 Bikdeli B, Madhavan MV, Gupta A, et al; Global COVID-19 Thrombosis Collaborative Group. Pharmacological agents targeting thromboinflammation in COVID-19: review and implications for future research. Thromb Haemost 2020;120(07): 1004-1024

114 Zhai Z, Li C, Chen Y, et al; Prevention Treatment of VTE Associated with COVID-19 Infection Consensus Statement Group. Prevention and treatment of venous thromboembolism associated with coronavirus disease 2019 infection: a consensus statement before guidelines. Thromb Haemost 2020;120 (06):937-948

115 Wei JF, Huang FY, Xiong TY, et al. Acute myocardial injury is common in patients with COVID-19 and impairs their prognosis. Heart 2020;106(15):1154-1159

116 Chen $\mathrm{T}$, Wu D, Chen $\mathrm{H}$, et al. Clinical characteristics of 113 deceased patients with coronavirus disease 2019: retrospective study. BMJ 2020;368:m1091

117 Gattinoni L, Coppola S, Cressoni M, Busana M, Rossi S, Chiumello D. COVID-19 does not lead to a "typical" acute respiratory distress syndrome. Am J Respir Crit Care Med 2020;201(10): $1299-1300$

118 Ramirez LMP, Caballero MC, de la Torre IM, et al. Hospital readmissions of discharged patients with COVID-19. medRxiv 2020. Doi: $10.1101 / 2020.05 .31 .20118455$

119 Chen J, Fan H, Zhang L, et al. Retrospective analysis of clinical features in 101 death cases with COVID-19. medRxiv 2020. Doi: $10.1101 / 2020.03 .09 .20033068$
120 Driggin E, Madhavan MV, Bikdeli B, et al. Cardiovascular considerations for patients, health care workers, and health systems during the COVID-19 pandemic. J Am Coll Cardiol 2020;75(18): 2352-2371

121 Costabel JP, Burgos LM, Trivi M. The significance of troponin elevation in atrial fibrillation. J Atr Fibrillation 2017;9(06):1530

122 Peretto G, Sala S, Rizzo S, et al. Ventricular arrhythmias in myocarditis: characterization and relationships with myocardial inflammation. J Am Coll Cardiol 2020;75(09):1046-1057

123 Tavazzi G, Pellegrini C, Maurelli M, et al. Myocardial localization of coronavirus in COVID-19 cardiogenic shock. Eur J Heart Fail 2020;22(05):911-915

124 Zeng JH, Liu YX, Yuan J, et al. First case of COVID-19 complicated with fulminant myocarditis: a case report and insights. Infection 2020;48(05):773-777

125 Doyen D, Moceri P, Ducreux D, Dellamonica J. Myocarditis in a patient with COVID-19: a cause of raised troponin and ECG changes. Lancet 2020;395(10235):1516

126 Guzik TJ, Mohiddin SA, Dimarco A, et al. COVID-19 and the cardiovascular system: implications for risk assessment, diagnosis, and treatment options. Cardiovasc Res 2020;116(10): 1666-1687

127 Guo T, Fan Y, Chen M, et al. Cardiovascular implications of fatal outcomes of patients with coronavirus disease 2019 (COVID-19). JAMA Cardiol 2020;5(07):811-818

128 Ferrari R. RAAS inhibition and mortality in hypertension. Glob Cardiol Sci Pract 2013;2013(03):269-278

129 Bavishi C, Maddox TM, Messerli FH. Coronavirus disease 2019 (COVID-19) infection and renin angiotensin system blockers. JAMA Cardiol 2020;5(07):745-747

130 Guazzi M, Moroni A. The dilemma of renin-angiotensin system inhibitors in coronavirus disease 2019 (COVID-19): insights into lung fluid handling and gas exchange in heart failure patients. Eur J Heart Fail 2020;22(06):926-928

131 Kuster GM, Pfister O, Burkard T, et al. SARS-CoV2: should inhibitors of the renin-angiotensin system be withdrawn in patients with COVID-19? Eur Heart J 2020;41(19):1801-1803

132 Keidar S, Gamliel-Lazarovich A, Kaplan M, et al. Mineralocorticoid receptor blocker increases angiotensin-converting enzyme 2 activity in congestive heart failure patients. Circ Res 2005;97 (09):946-953

133 Zhong JC, Ye JY, Jin HY, et al. Telmisartan attenuates aortic hypertrophy in hypertensive rats by the modulation of ACE2 and profilin-1 expression. Regul Pept 2011;166(1-3):90-97

134 Ferrario CM, Jessup J, Chappell MC, et al. Effect of angiotensinconverting enzyme inhibition and angiotensin II receptor blockers on cardiac angiotensin-converting enzyme 2. Circulation 2005;111(20):2605-2610

135 Zheng Y-Y, Ma Y-T, Zhang J-Y, Xie X. Reply to: 'Interaction between RAAS inhibitors and ACE2 in the context of COVID19'. Nat Rev Cardiol 2020;17(05):313-314

136 Albini A, Di Guardo G, Noonan DM, Lombardo M. The SARS-CoV2 receptor, ACE-2, is expressed on many different cell types: implications for ACE-inhibitor- and angiotensin II receptor blocker-based cardiovascular therapies. Intern Emerg Med 2020;15(05):759-766

137 Milne S, Yang CX, Timens W, Bossé Y, Sin DD. SARS-CoV-2 receptor ACE2 gene expression and RAAS inhibitors. Lancet Respir Med 2020;8(06):e50-e51

138 Mancia G, Rea F, Ludergnani M, Apolone G, Corrao G. Reninangiotensin-aldosterone system blockers and the risk of COVID19. N Engl J Med 2020;382(25):2431-2440

139 Reynolds HR, Adhikari S, Pulgarin C, et al. Renin-angiotensinaldosterone system inhibitors and risk of covid-19. N Engl J Med 2020;382(25):2441-2448

140 Rossi GP, Sanga V, Barton M. Potential harmful effects of discontinuing ACE-inhibitors and ARBs in COVID-19 patients. eLife 2020;9:e57278 
141 ClinicalTrials.gov. A study to evaluate the safety and efficacy of tocilizumab in patients with severe COVID-19 pneumonia. US National Library of Medicine. Available at: https://clinicaltrials.gov/ct2/show/NCT04320615. Accessed September 28, 2020

142 ClinicalTrials.gov. observational study, use of canakinumab administered subcutaneously in the treatment COVID-19 pneumonia. US National Library of Medicine. Available at: https://www. clinicaltrials.gov/ct2/show/NCT04348448. Accessed September 28,2020

143 ClinicalTrials.gov. Efficacy and safety of emapalumab and anakinra in reducing hyperinflammation and respiratory distress in patients with COVID-19 infection. US National Library of Medicine. Available at: https://www.clinicaltrials.gov/ct2/show/ NCT04324021. Accessed September 28, 2020

144 Ledford H. Coronavirus breakthrough: dexamethasone is first drug shown to save lives. Nature 2020;582(7813):469

145 Vandevyver S, Dejager L, Tuckermann J, Libert C. New insights into the anti-inflammatory mechanisms of glucocorticoids: an emerging role for glucocorticoid-receptor-mediated transactivation. Endocrinology 2013;154(03):993-1007
146 Johannesdottir SA, Horváth-Puhó E, Dekkers OM, et al. Use of glucocorticoids and risk of venous thromboembolism: a nationwide population-based case-control study. JAMA Intern Med 2013;173(09):743-752

147 van Giezen JJJ, Brakkee JGP, Dreteler GH, Bouma BN, Jansen JWCM. Dexamethasone affects platelet aggregation and fibrinolytic activity in rats at different doses which is reflected by their effect on arterial thrombosis. Blood Coagul Fibrinolysis 1994;5 (02):249-255

148 Violi F, Pastori D, Cangemi R, Pignatelli P, Loffredo L. Hypercoagulation and antithrombotic treatment in coronavirus 2019: a new challenge. Thromb Haemost 2020;120(06):949-956

149 Jin HM, Pan Y. Angiotensin type-1 receptor blockade with losartan increases insulin sensitivity and improves glucose homeostasis in subjects with type 2 diabetes and nephropathy. Nephrol Dial Transplant 2007;22(07):1943-1949

150 Pueyo ME, Gonzalez W, Nicoletti A, Savoie F, Arnal JF, Michel JB. Angiotensin II stimulates endothelial vascular cell adhesion molecule-1 via nuclear factor-kappaB activation induced by intracellular oxidative stress. Arterioscler Thromb Vasc Biol 2000;20(03):645-651 